\title{
2019 Annual Technology Baseline
}

Laura Vimmerstedt, Sertaç Akar, Chad Augustine, Philipp Beiter, Wesley Cole, David Feldman, Parthiv Kurup, Eric Lantz, Robert Margolis, Ashwin Ramdas, Tyler Stehly, and Craig Turchi (NREL), and Debo Oladosu (ORNL)

August 22, 2019 


\section{Agenda}

- ATB Overview

- Cost and Performance Comparisons

- Technology-Specific Highlights

- Standard Scenarios Preview 
ATB Overview 


\section{The ATB targets analytic}

transparency and consistency.

Objective: Develop and publish renewable energy technology cost and performance scenarios that are credible, comparable, transparent, and reflect potential technology advancement

\section{EERE ${ }^{a}$ Analysis Consistency}

- Ensure consistent assumptions across technologies

- Provide comparability across EERE/national laboratory publications

a U.S. Department of Energy Office of Energy Efficiency and Renewable Energy (EERE)

\section{Third-Party Analysis}

- Provides access to assumptions

- Leverages national laboratory expertise 
Now in its fifth year, the ATB is frequently used at NREL...

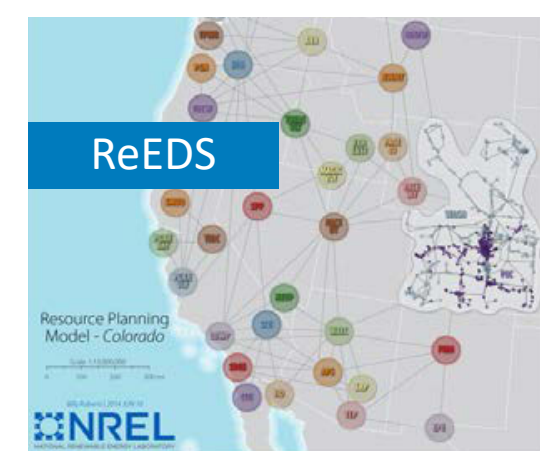

Resource Planning Model

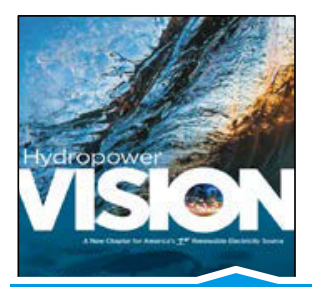

Hydropower

Vision
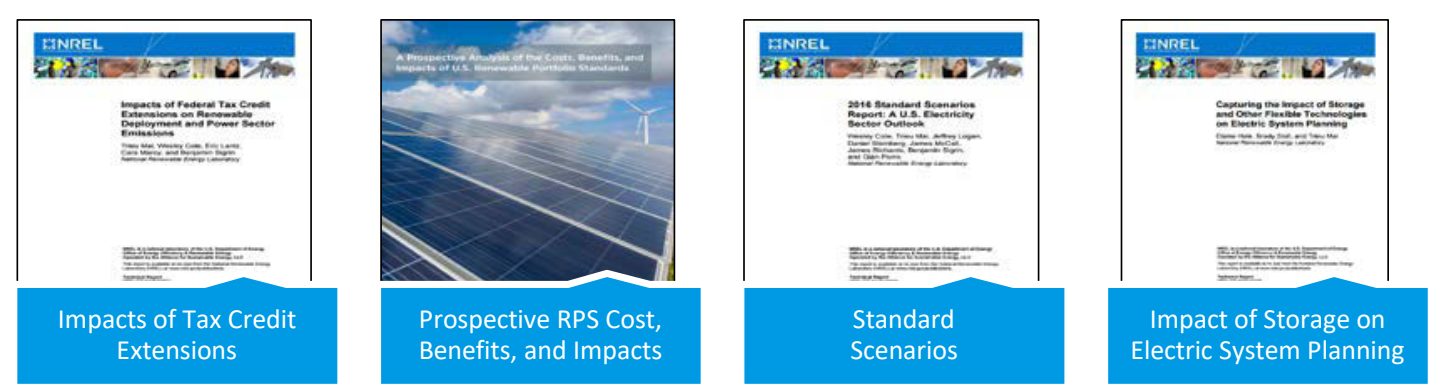

Important Scenario Analyses Used ATB Projections

Electric System Planning

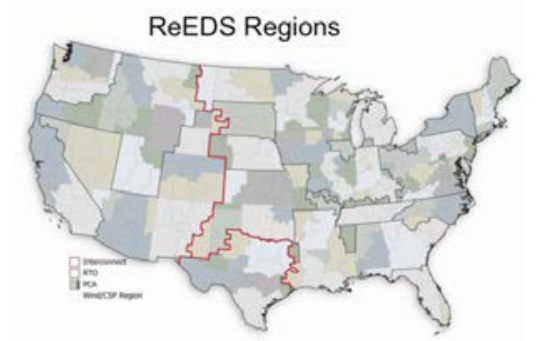

RPM

Regional Energy Deployment System 


\section{... and is used by planners, academics, analysts, and others.}

\section{Federal Agencies}

(Bureau of Land Management, U.S. Department of Energy and labs, U.S. Environmental Protection Agency)

\section{Consultants}

(Rhodium Group, Navigant, M.J. Bradley \& Associates, Analysis Group)

State Energy Offices

(Hawaii, Michigan)

\section{Grid Operators}

(North American Electric Reliability Corporation,

Midcontinent Independent System Operator,

Pennsylvania-New Jersey-Maryland

Interconnection, New York Independent System Operator)

\section{Non-Profits}

(Resources for the Future, Environmental Defense Fund, Union of Concerned Scientists)

\section{International}

(Chilean Ministry of Energy, Global Carbon Capture and Storage Institute, Institute, Canadian Institute for Integrated Energy Systems)

\section{Utilities}

(Hawaii Electric Company, Dominion Energy)

\section{Academia}

(Stanford University, University of Maryland, University of Texas, Duke University)

Media

(Utility Dive) 
The ATB data are inputs for the Standard Scenarios.

\section{Annual Technology Baseline}

Cost and performance assumptions for renewable and conventional technologies

Standard Scenarios

Ensemble of future scenarios of the U.S. electric power sector 


\section{The ATB includes:}

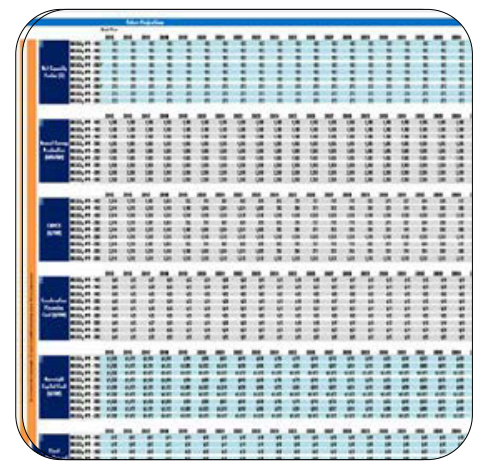

\section{Spreadsheet}

- Shows calculations

- Cost and performance projections, 2017-2050

- Capacity factor

- Operations and maintenance costs

- Capital expenditures (CAPEX)

- Financing assumptions

- Levelized cost of energy (LCOE)
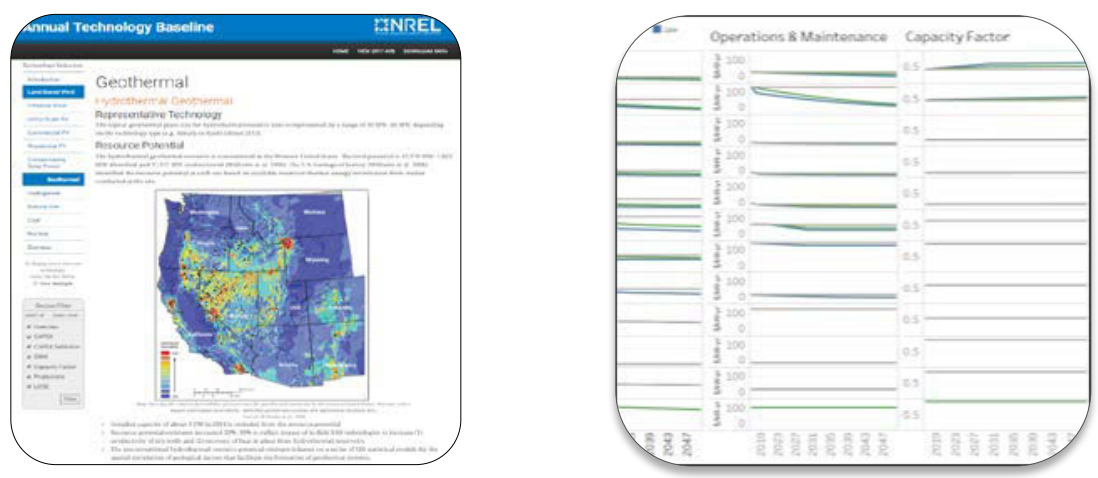

\section{Web App}

- atb.nrel.gov

- User guidance

- Additional analyses

- Methodologies

- Charts and figures

- Historical trends and comparison to other projections (e.g., EIA)

\section{Tableau Workbook and}

Formatted Data

- Summary of selected data (no calculations)

- Interactive charts

- Visual exploration

- Cost and performance projections, 2017-2050

- Capacity factor

- Operations and maintenance costs

- Capital expenditures (CAPEX)

- Financing assumptions

- Levelized cost of energy (LCOE)

- Structured format 


\section{The ATB provides cost and performance data.}

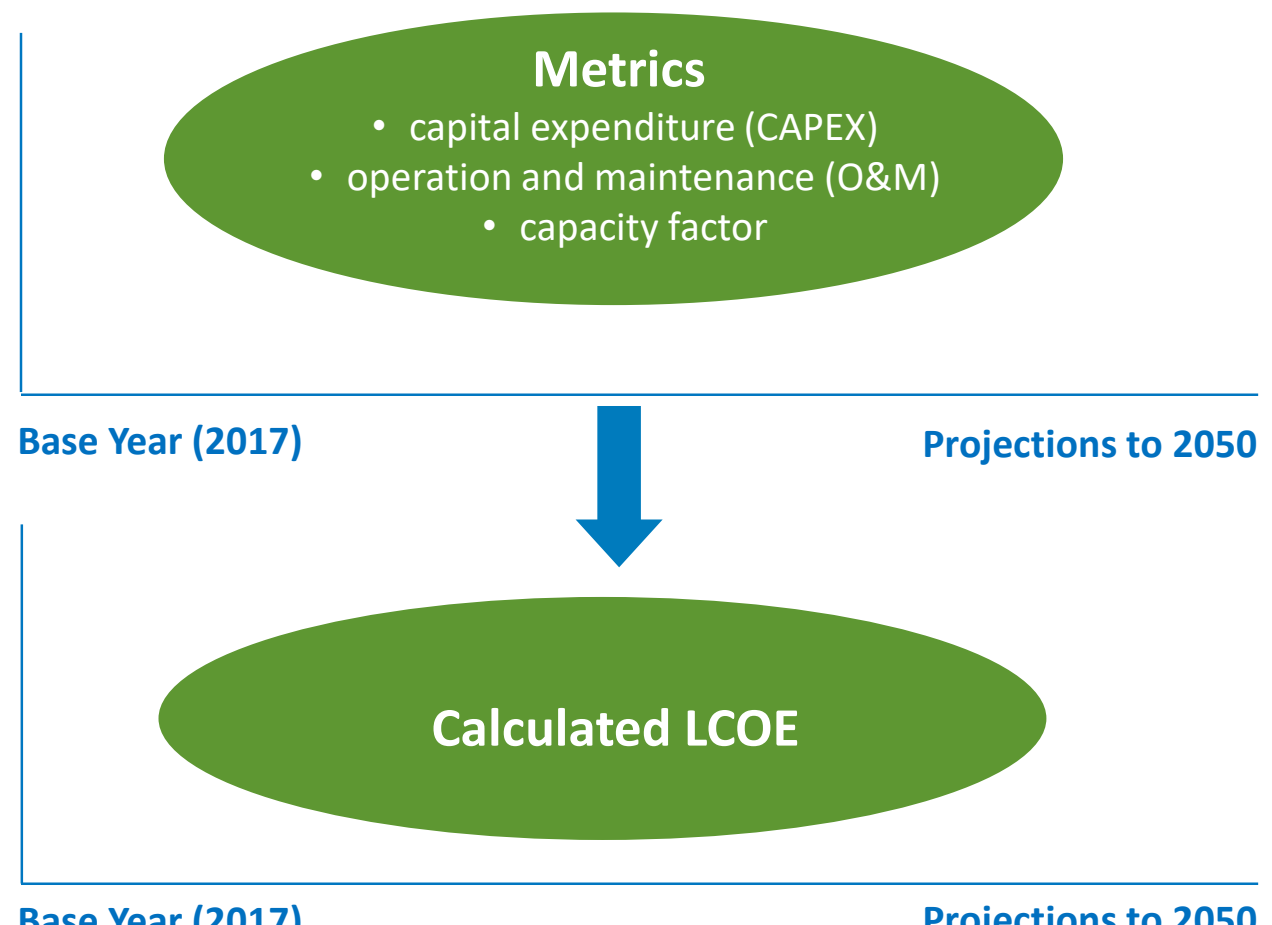

Cost and performance data are:

- Provided for each:
- Year
- Metric
- Resource
- Technology
- Technology cost scenario

- Used to calculate LCOE for each financial assumptions scenario.

LCOE is provided as a summary metric but is not used as a ReEDS model input. Its limitations are described in the documentation. The user can select or specify financial assumptions for calculating LCOE. 


\section{Technologies} Covered

\section{Renewable Energy}

Technologies (EERE/NREL)

Wind

- Land-based

- Offshore

\section{Solar}

- Utility PV

- Commercial and industrial PV

- Residential PV

- Concentrating solar power (CSP)

\section{Hydropower}

- Non-powered dams (NPD)

- New stream-reach dDevelopment (NSD)

Geothermal (Flash and Binary)

- Hydrothermal

- Near-field enhanced geothermal systems (EGS)

- Deep EGS

\section{Conventional and Carbon}

Capture and Storage

(EIA AEO 2019)

\section{Natural Gas}

- Natural gas combined cycle (NGCC)

- NGCC-carbon capture and storage (CCS)

- Combustion turbine (CT)

\section{Conventional}

- Integrated gasification combinedcycle (IGCC)

- $30 \%$ CCS

\section{Nuclear}

- Gen 3

\section{Biopower}

- Dedicated

- Co-fired

\section{Storage}

- Utility-scale four-hour battery storage 


\section{Methodology Overview: Three Steps}

\section{Define resource bins for each technology}

Group range of resources for continental United States into bins with common resource quality and characteristics, or develop representative plants

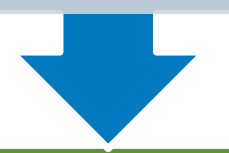

\section{Develop cost and performance data}

Develop base year and projected values for Constant, Mid, and Low technology cost scenarios are developed for CAPEX, capacity factor, and operation and maintenance (O\&M)

\section{Calculate LCOE}

Use selected financial assumptions to calculate LCOE from CAPEX, capacity factor, and O\&M 


\section{Step 1: Define Technologies/Resource Bin Categories}

\section{Technology Bins Distinguishing Characteristics}

Land-based wind

Offshore wind

Utility-scale, commercial, and residential PV

\begin{tabular}{lll} 
CSP & 3 & Direct normal solar irradiance \\
\hline Geothermal & $6^{\mathrm{a}}$ & Hydrothermal, EGS, binary or flash systems, reservoir temperature \\
\hline Hydropower & $8^{\mathrm{a}}$ & Non-powered dams, new stream-reach development, head, and design capacity \\
\hline Natural gas & 6 & Combustion turbine, IGCC, CCS, and choice of capacity factor \\
\hline Coal & 8 & Pulverized coal, IGCC, CCS, and choice of capacity factor \\
\hline Nuclear & 1 & Not applicable \\
\hline Biopower & 2 & Dedicated or co-fired \\
\hline
\end{tabular}

Annual average wind speed

15 Fixed and floating foundations, distance from shore, water depth, and annual average wind speed

$5 \quad$ Horizontal solar irradiance resource level 


\section{Example of Technology/Resource Bins: Land-Based Wind}

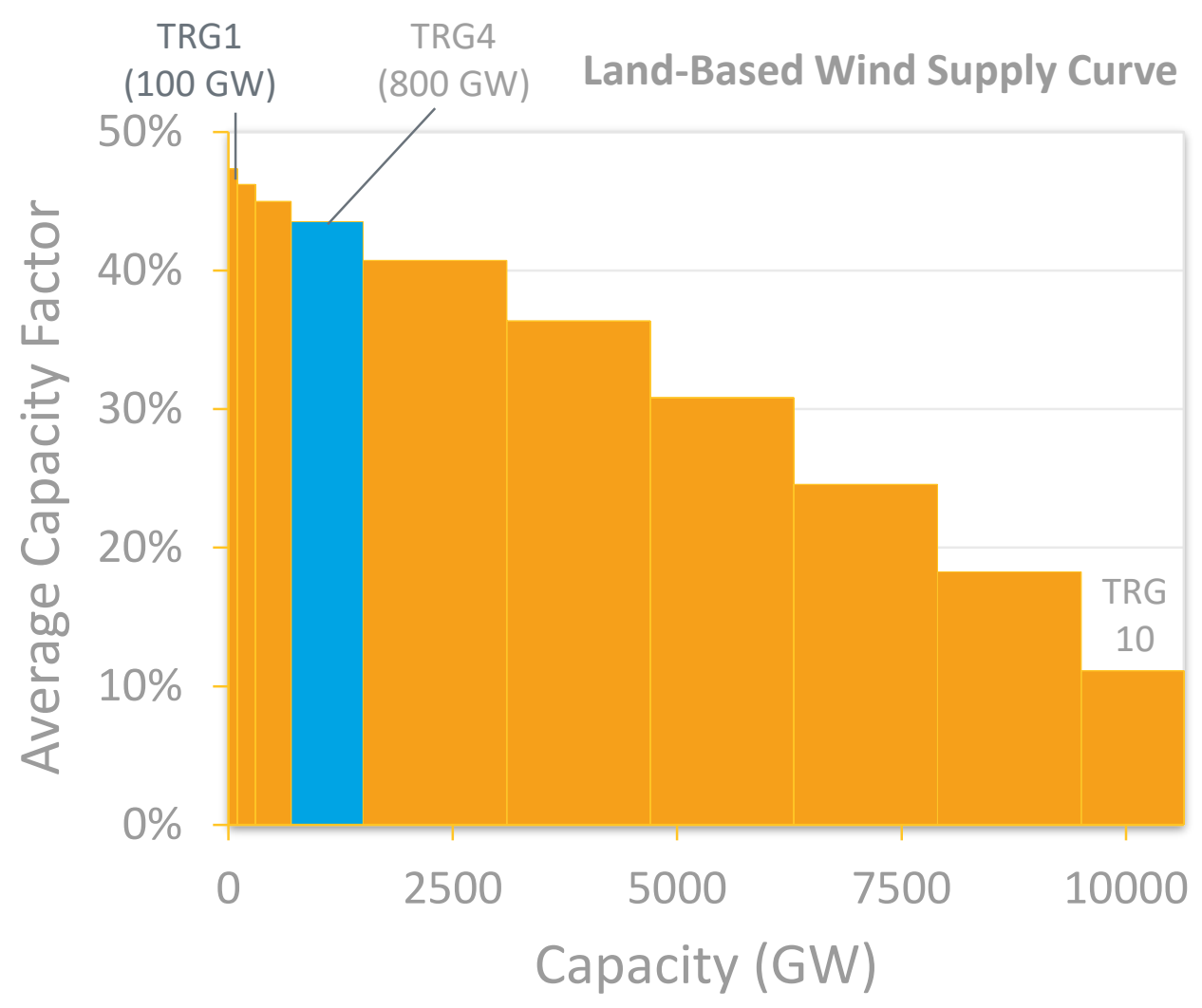

Land-based wind resources binned by cost and quality into 10 techno-resource groups (TRGs)

TRG4 identified as most representative of future installations 


\section{Step 2: Develop Cost and Performance Data}

Base Year (2017): Informed by market reports, market data, and bottom-up modeling

Projections: Generally rely on bottom-up modeling and published studies; qualitatively harmonized to three projection scenarios:

\section{Constant} Technology Cost

- Current technology costs held constant

- Represents limited/no technology improvement

- No additional R\&D

\section{Mid \\ Technology Cost}

- Improvements characterized as "likely" or "not surprising"

- Continued public and private R\&D

- Continued deployment and market growth

\section{Low Technology Cost}

- Improvements at the "limit of surprise"

- Not an absolute low bound

- Increased public and private R\&D, breakthroughs

- Accelerated market growth 


\section{Sources of Base Year (2017)}

\section{Technology}

Land-based wind

power plants

Offshore wind

power plants

Utility, residential, and commercial PV plants

Concentrating solar power plants

Geothermal plants

Hydropower plants

Fossil, nuclear, and biopower plants

\section{Source}

Bottom-up modeling (Stehly, Beiter, Heimiller, and Scott 2018); compared to wind market data reports (Wiser and Bolinger 2018); methodology updated from Wind Vision (DOE and NREL 2015)

Bottom-up modeling (Beiter et al. 2016); methodology and data updated to the latest cost and technology trends observed in the U.S. and European offshore wind markets (Beiter, Spitsen, Musial, and Lantz 2019), (Musial et al. 2019)

Bottom-up cost modeling (Fu, Feldman, and Margolis 2018)

Bottom-up cost modeling from Turchi et al. (2019) and an NREL survey of projects under construction for operation in 2018

Bottom-up cost modeling using GETEM and inputs from the GeoVision BAU scenario (DOE 2019)

Hydropower Vision (DOE 2016), bottom-up cost modeling from Hydropower Baseline Cost Modeling (O'Connor et al. 2015)

Annual Energy Outlook (EIA 2019) reported costs 


\section{Sources of Projections (to 2050)}

\begin{tabular}{|c|c|c|c|c|c|}
\hline Technology & Methods & Source & ATB Mid & ATB Low & Notes \\
\hline $\begin{array}{l}\text { Land-Based } \\
\text { Wind }\end{array}$ & $\begin{array}{l}\text { Bottom-up } \\
\text { analysis; } \\
\text { learning }\end{array}$ & $\begin{array}{l}\text { Stehly et al. } \\
\text { Forthcoming; Dykes } \\
\text { et al. } 2017\end{array}$ & $\begin{array}{l}\text { Bottom-up analysis of } \\
\text { median wind R\&D } \\
\text { opportunities }\end{array}$ & $\begin{array}{l}\text { Bottom-up analysis of next } \\
\text { generation wind R\&D } \\
\text { opportunities }\end{array}$ & $\begin{array}{l}\text { Mid and Low reflect relative LCOE decomposed } \\
\text { to CAPEX, capacity factor, O\&M; learning rates } \\
\text { (Wiser, Jenni, et al. 2016) }\end{array}$ \\
\hline Offshore Wind & $\begin{array}{l}\text { Expert } \\
\text { elicitation }\end{array}$ & $\begin{array}{l}\text { Valpy et al. 2017; } \\
\text { Hundleby et al. } 2017\end{array}$ & $\begin{array}{l}\text { Reduction from base } \\
\text { year from expert } \\
\text { elicitation } 50 \% \\
\text { probability }\end{array}$ & $\begin{array}{l}\text { Reduction relative to Mid case } \\
\text { informed by bottom-up and } \\
\text { cost modeling }\end{array}$ & $\begin{array}{l}\text { Low scenario has twice the cost reduction rates } \\
\text { of Mid scenario }\end{array}$ \\
\hline $\begin{array}{l}\text { Solar PV (utility } \\
\text { and distributed) }\end{array}$ & $\begin{array}{l}\text { Literature } \\
\text { survey (CAPEX), } \\
\text { single pathway } \\
\text { (O\&M) }\end{array}$ & $\begin{array}{l}\text { Internal NREL analysis } \\
\text { (Feldman) }\end{array}$ & $\begin{array}{l}\text { Based on median of } \\
\text { literature sample }\end{array}$ & $\begin{array}{l}\text { Based on lower bound of } \\
\text { literature sample }\end{array}$ & $\begin{array}{l}\text { Long term: forecasts published in last three years } \\
\text { Short term: forecasts published in last two years }\end{array}$ \\
\hline $\begin{array}{l}\text { CSP (10 hours } \\
\text { thermal } \\
\text { storage) }\end{array}$ & $\begin{array}{l}\text { Pathway } \\
\text { analysis, } \\
\text { learning, } \\
\text { literature survey }\end{array}$ & $\begin{array}{l}\text { NREL analysis (Kurup) } \\
\text { and On the Path to } \\
\text { SunShot }\end{array}$ & $\begin{array}{l}\text { Based on median of } \\
\text { literature sample and } \\
\text { expert assessment }\end{array}$ & $\begin{array}{l}\text { Based on lower bound of } \\
\text { literature sample and on Power } \\
\text { to Change Report (IRENA 2016) }\end{array}$ & $\begin{array}{l}\text { Low projection informed by pathway analysis } \\
\text { combined with learning rates Mid projection } \\
\text { based on literature sample and expert } \\
\text { assessment }\end{array}$ \\
\hline $\begin{array}{l}\text { Hydropower } \\
\text { (NPD and NSD) }\end{array}$ & $\begin{array}{l}\text { Multiple } \\
\text { pathway, expert } \\
\text { input, learning }\end{array}$ & $\begin{array}{l}\text { Hydropower Vision } \\
\text { (DOE 2016) }\end{array}$ & $\begin{array}{l}\text { Hydropower Vision } \\
\text { (DOE 2016) Reference } \\
\text { scenario }\end{array}$ & $\begin{array}{l}\text { Hydropower Vision (DOE 2016) } \\
\text { Advanced Technology scenario }\end{array}$ & $\begin{array}{l}\text { Projections informed by industry expertise, } \\
\text { identifiable potential future technology and } \\
\text { process advancements, EIA minimum learning }\end{array}$ \\
\hline Geothermal & $\begin{array}{l}\text { Pathway } \\
\text { analysis, } \\
\text { minimum } \\
\text { learning }\end{array}$ & $\begin{array}{l}\text { DOE 2019; AEO2015 } \\
\text { (EIA 2015) }\end{array}$ & $\begin{array}{l}\text { GeoVision Business-as- } \\
\text { Usual (BAU) scenario } \\
\text { plus-5\% CAPEX by } 2035\end{array}$ & $\begin{array}{l}\text { GeoVision Technology } \\
\text { Improvement }(\mathrm{TI}) \text { scenario }\end{array}$ & $\begin{array}{l}\text { GeoVision study contains details of BAU and TI } \\
\text { scenario assumptions } \\
\text { NREL । } 16\end{array}$ \\
\hline
\end{tabular}




\section{Step 3: Calculate Levelized Cost of Energy (LCOE)}

Levelized Cost of Energy $=$

Fixed Charge Rate $\times$ Capital Expenditures + Fixed Operations and Maintenance Cost Capacity Factor $\times 8760$ hours/year

+ Variable Operations and Maintenance Cost

+ Fuel Cost

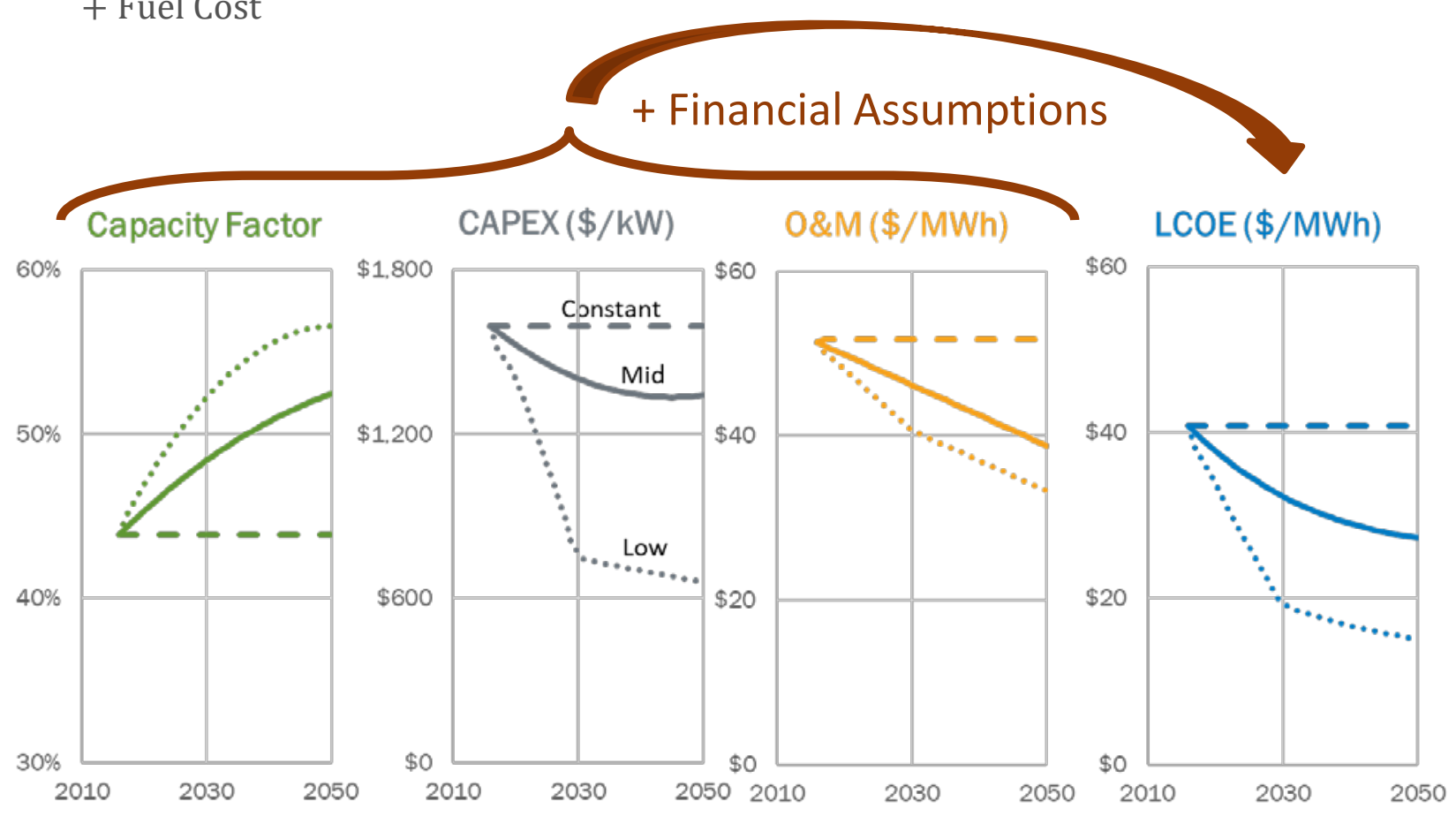

LCOE is a summary metric with important limitations. See documentation.

"Capacity factor" refers to utilization for geothermal, hydropower, coal, gas, nuclear, and biopower. 
Summary of 2019 ATB

Technology Cost and

Performance 


\section{Summary of Changes from 2018 ATB to 2019 ATB}

- Modified the values in the two financial cases (R\&D Only and R\&D + Market) to reflect current assessments; market case no longer includes tariff effects.

- Added a sensitivity case with cost recovery period equal to technological life comparison

- New products: Tableau workbook and formatted data

- Base year is now 2017, and dollar year is now 2017. 


\section{Updates by Technology}

- Wind: New methodology for projections entails bottom-up technology analysis and cost modeling plus learning rates, including high technology innovation attributable to R\&D in the low technology cost case.

- Offshore Wind: Base Year uses spatial analysis using updated bottom-up cost parameters and technology analysis; projections based on expert assessment from literature in combination with technology innovation pathway.

- Utility PV: Base year uses bottom-up cost modeling

- CSP: Component and system cost estimates for Base Year now reference a 2017 industry survey, and a 2018 cost analysis of recent market developments.

- Geothermal: New data are now consistent with GeoVision Study.

- Li-ion Battery Storage: Updated projections are based on a new literature review. 


\section{CAPEX Comparison, 2030}

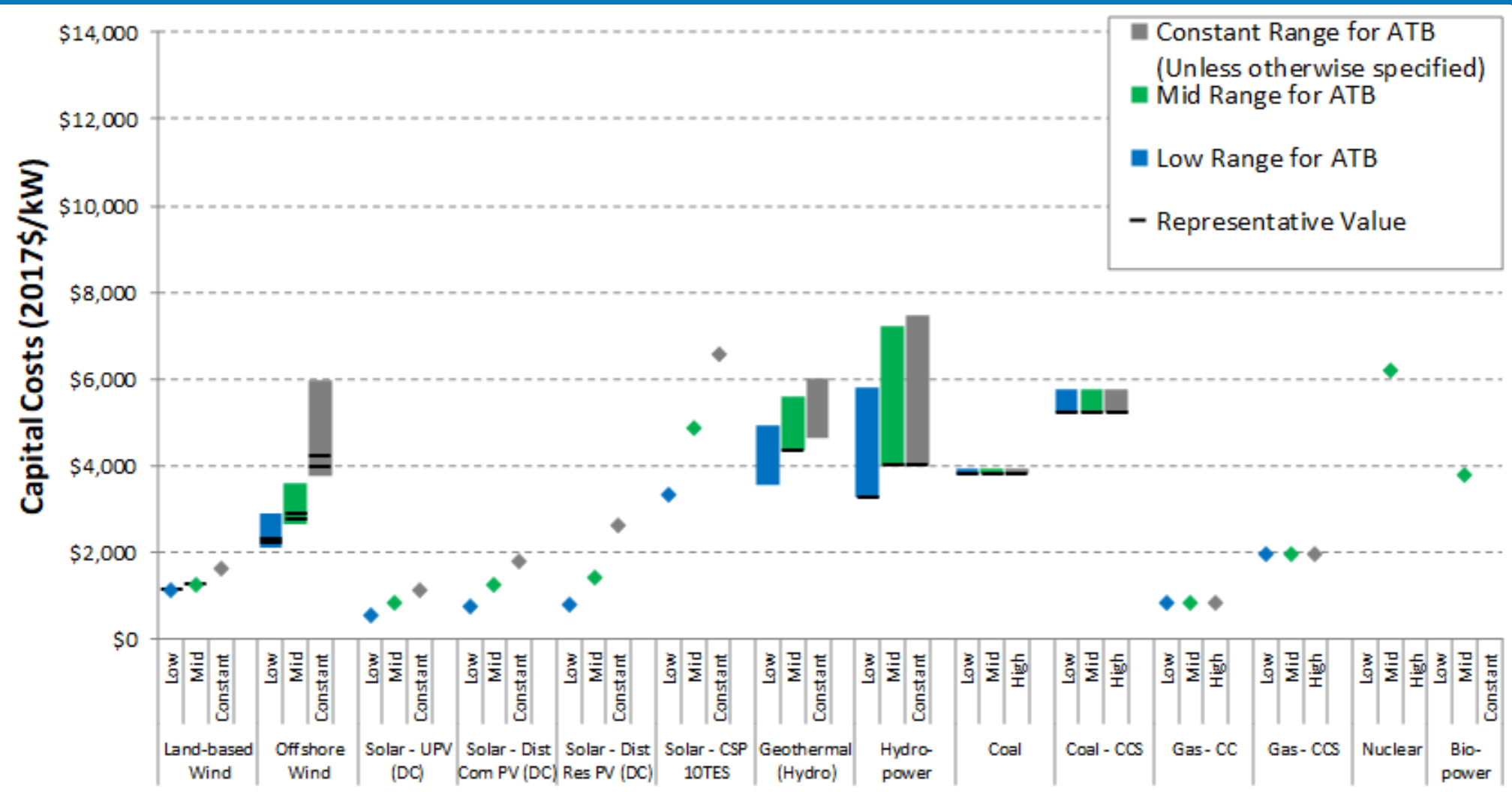

2019 ATB CAPEX range by technology for $\mathbf{2 0 3 0}$

Source: National Renewable Energy Laboratory Annual Technology Baseline (2019), http://atb.nrel.gov 


\section{Capacity Factor Comparison, 2030}

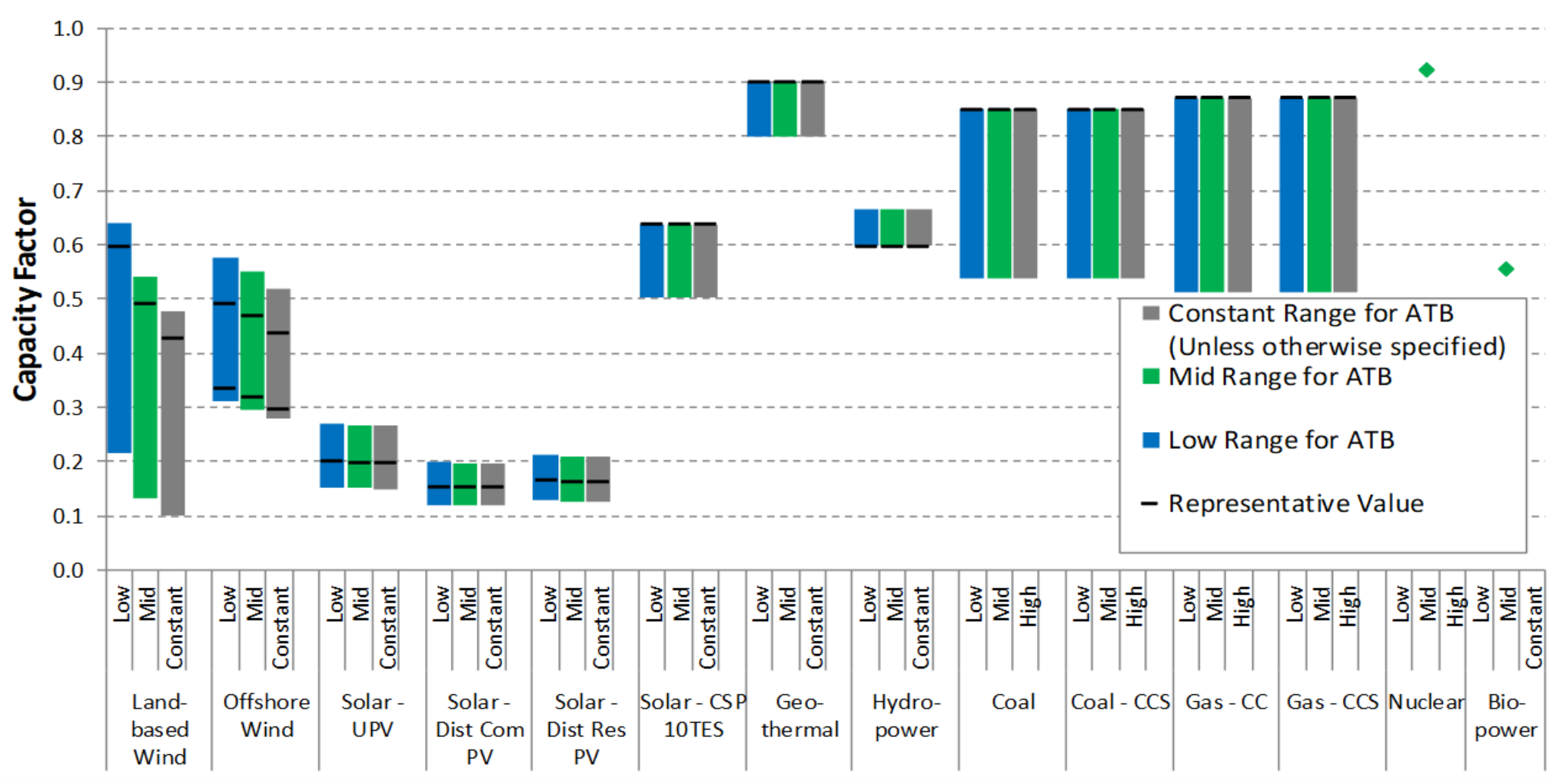

2019 ATB capacity factor range by technology for 2030

Source: National Renewable Energy Laboratory Annual Technology Baseline (2019), http://atb.nrel.gov 


\section{LCOE Comparison: Sensitivity to Financial Assumptions Case}

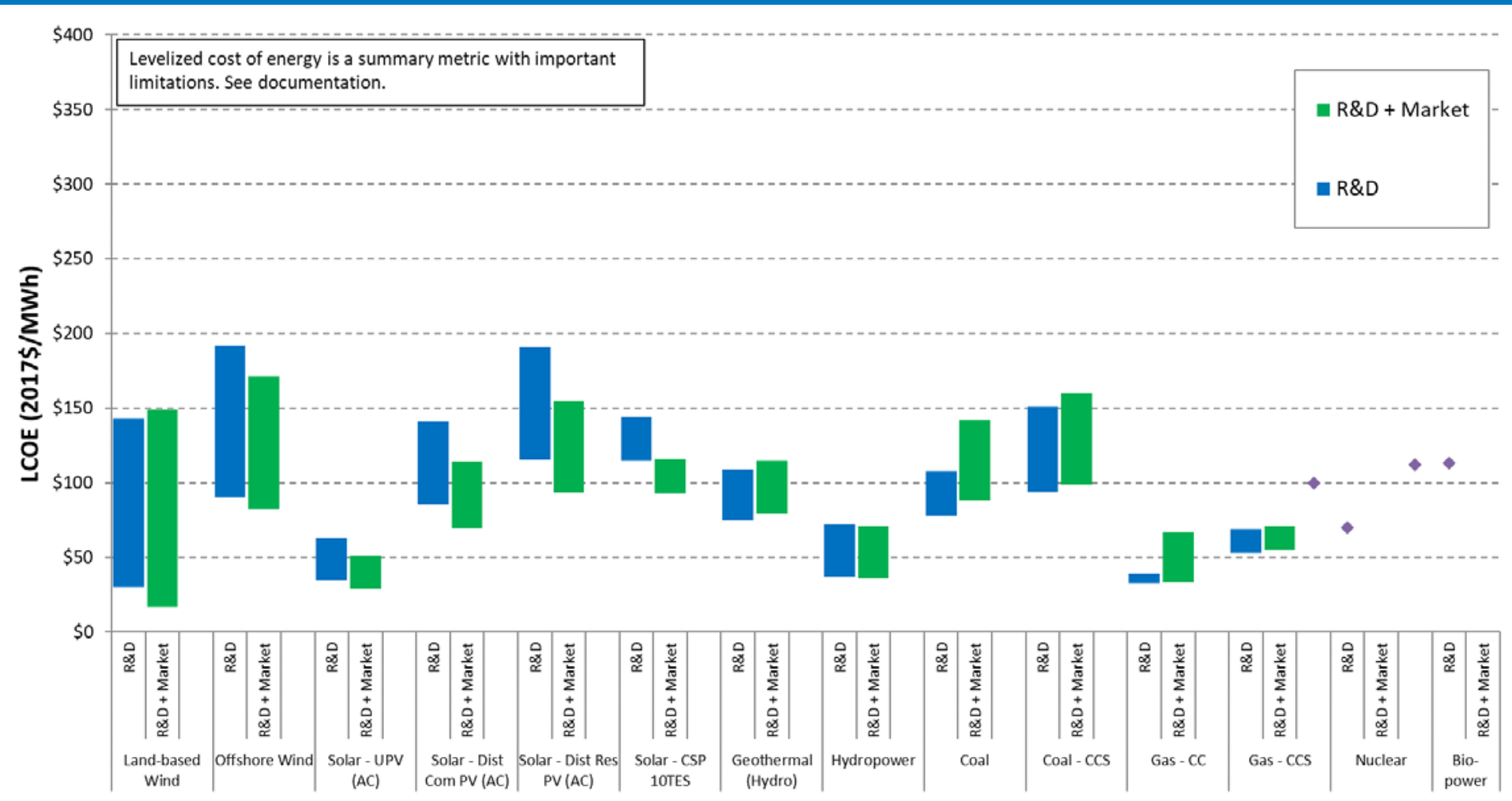

- $R \& D=R \& D$ Only

Financial

Assumptions

(constant

background rates, no

tax or tariff changes)

- $R \& D+$ Market $=R \& D$

Only + Market

Financial

Assumptions

(dynamic background rates, taxes, and tariffs)

Sensitivity of 2017 base year LCOE to project finance parameters

Source: National Renewable Energy Laboratory Annual Technology Baseline (2019), http://atb.nrel.gov 


\section{LCOE Comparison: Sensitivity to Cost Recovery Period}

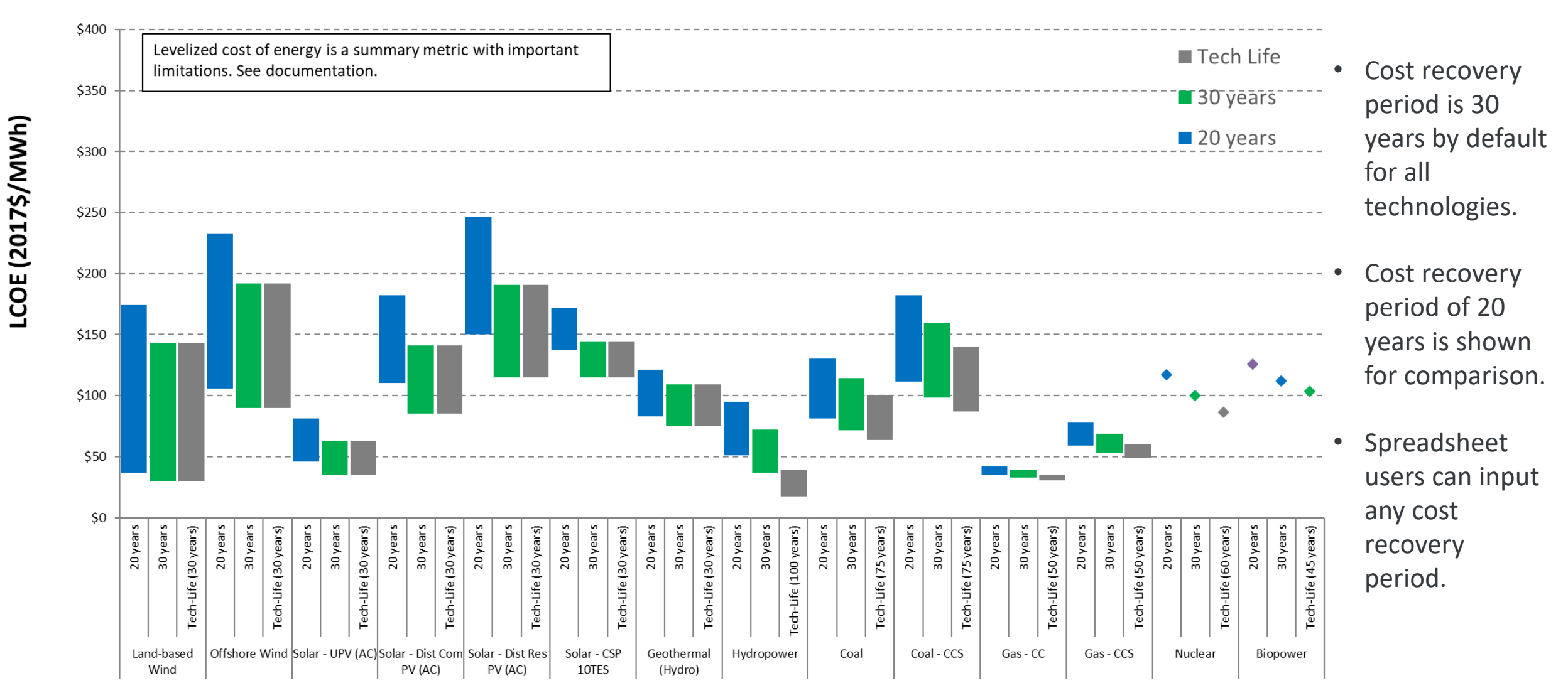

2019 ATB base year LCOE sensitivity to cost recovery period of plant

Source: National Renewable Energy Laboratory Annual Technology Baseline (2019), http://atb.nrel.gov 
Technology-Specific

Technolog
Highlights 


\section{ATB 2018 vs. ATB 2019 Comparison for R\&D Financials}

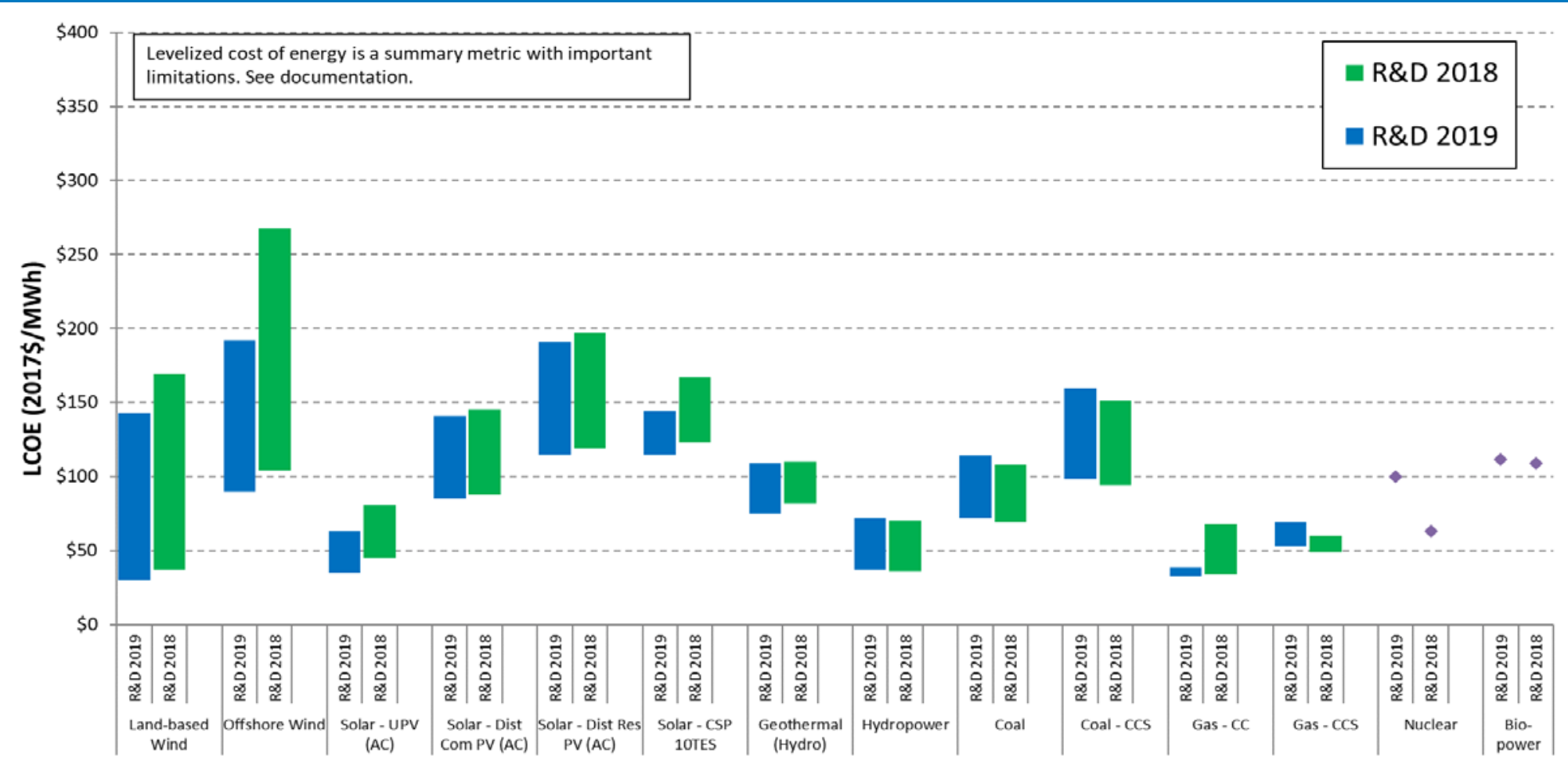

Comparison of LCOE in 2017 between 2019 ATB and 2018 ATB with R\&D finance parameters Source: National Renewable Energy Laboratory Annual Technology Baseline (2019), http://atb.nrel.gov 


\section{Land-Based Wind}

- Technology Representation

- Ten techno-resource groups (TRGs) spanning available resources

- TRG 4 representative of current installations

- $\quad$ Projection Methods

- Conducted expert assessment to characterize turbine technology in 2030

- Performed bottom-up cost analysis for low, mid, and high scenarios in 2030

- Applied learning curve methodology for cost reductions from 2030 to 2050

- Conducted expert elicitation and literature review to inform and verify cost reduction trajectories

- Justification

- Market trends show decreasing costs, attributable to larger turbines; more diverse turbines tailored to site; taller towers; improved siting; improved O\&M procedures and component reliability; manufacturing and design efficiencies; innovative control, design, and materials supply chains.

- Expert elicitation (Wiser et al. 2016) work becoming dated

- Bottom-up modeling enables more detailed understanding of how future turbine technologies and system performance impacts LCOE. 


\section{8 vs. 2019 LCOE: Land-Based Wind, TRG 4}

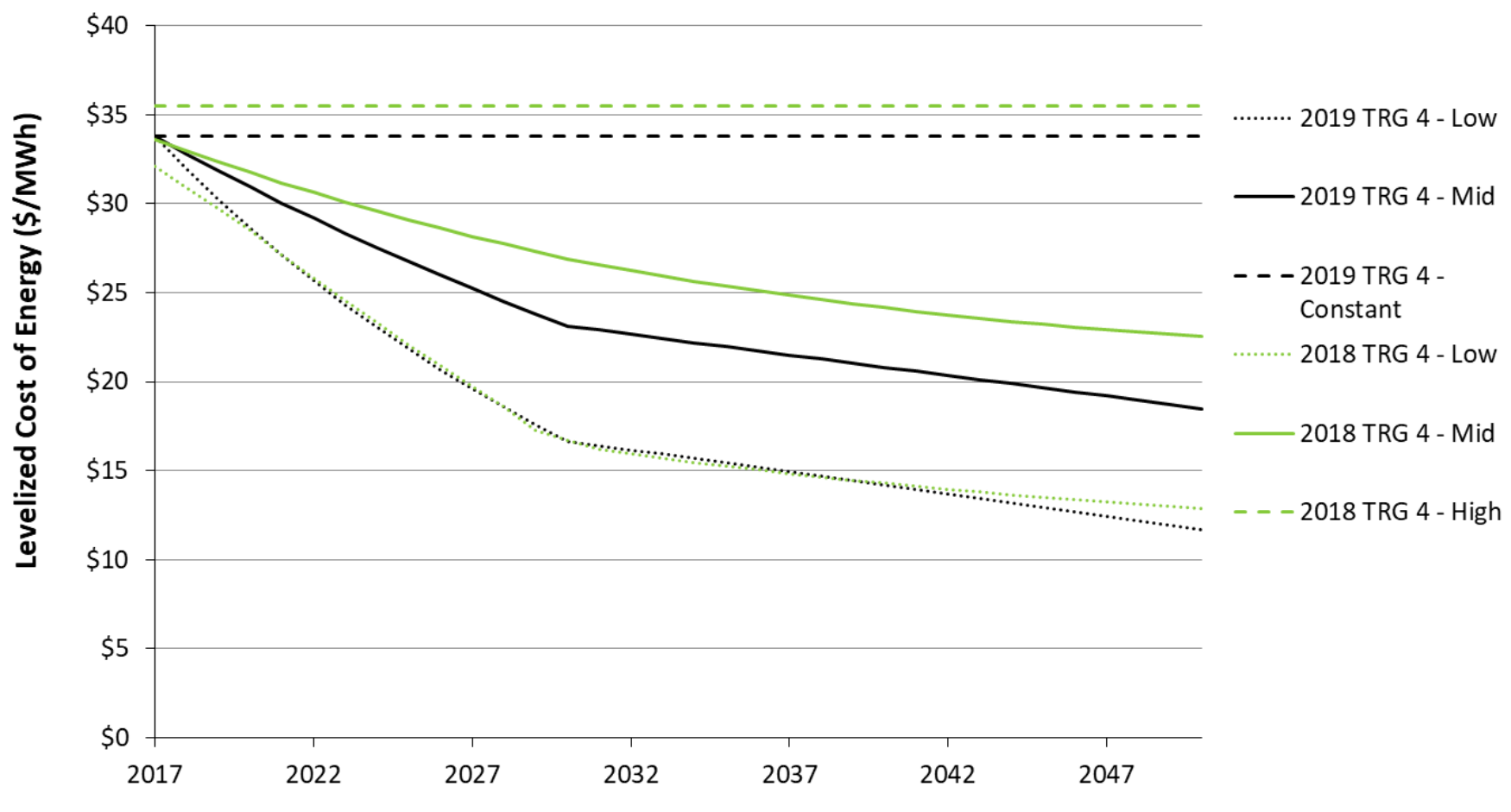

Land-based Wind ATB cost projections 2019 (R\&D only) compared to 2018 (R\&D only)

Source: National Renewable Energy Laboratory Annual Technology Baseline (2019), http://atb.nrel.gov 


\section{Offshore Wind}

- Technology Representation

- 15 Techno-Resource Groups (TRGs) span available resources

- TRGs 1-5 intended to represent fixed-bottom and TRGs 6-15 floating technology

- TRG 3 representative of expected near-medium term installations

- Projection Methods

- Expert elicitation and literature

- $\quad$ Mid = median of $50 \%$ LCOE probability

- Low $=$ expert assessment of potential R\&D advances

- Decompose LCOE reductions to CAPEX, capacity factor, and O\&M

- Justification

- Market trends show decreasing costs, attributable to larger turbines; increased competition in the production of primary components and installation; economies of scale; improved siting; improved O\&M procedures and component reliability; innovative control, design, and materials supply chains.

- Expert elicitation was getting older, so projections incorporate more up-to-date modeling and literature sources

- Internal analysis now uses more detailed information, which was informed by assessment of PPA pricing from first commercial-scale offshore wind farm in the U.S. (Vineyard Wind, 800-MW) (Beiter et al. 2019). 


\section{8 vs. 2019 LCOE: Offshore Wind, TRG3}

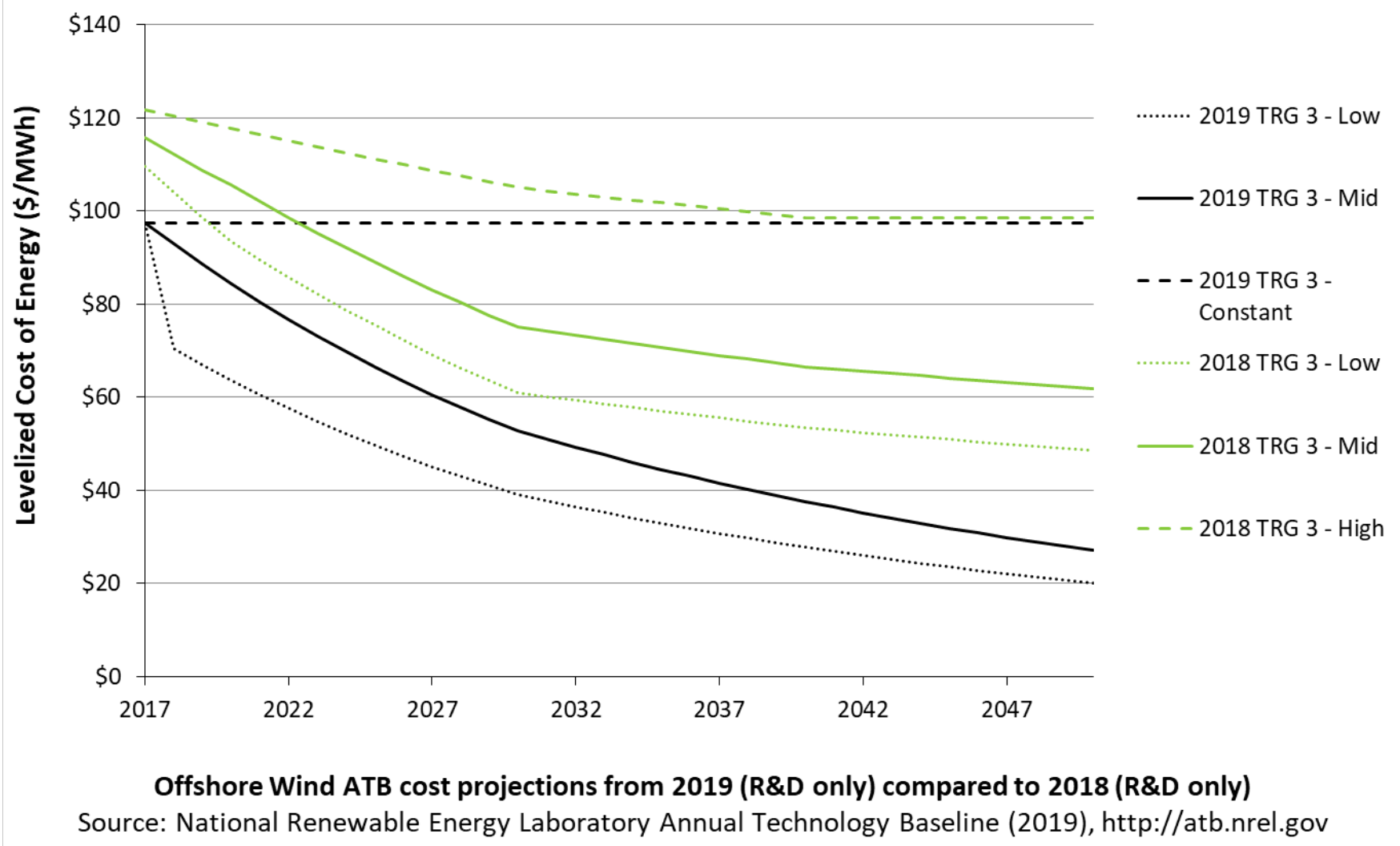




\section{Solar PV}

- Technology Representation

- $\quad$ Five capacity factors from representative locations

- $\quad 20 \%$, the mid case capacity factor for utility-scale PV, is lower than median of current U.S. installations in the field

- Capacity factor includes degradation; DC-to-AC conversion

- Projection Methods

_ $\quad$ Literature survey: utility/all: 11/25 projections and 9/10 institutions

- Mid based on median; Low based on low bound of literature; linear interpolations

- Through 2030: domestic only; after 2030 add global

- $\quad$ Adjusted to represent single-axis

- Justification

- Module cost reduction opportunities include efficiency and production-line throughput; thinner and novel semiconductor; economies of scale and low-cost manufacturing locations

- Balance of system opportunities include system size reduction from greater module efficiency, improved racking systems, supply chain optimization, power electronic improvements such as microinverters, and decreased installation costs and margins

- Updated literature now available; base year data concerns addressed

- Notes

- Updated pricing reflects a higher inverter loading ratio. 


\section{8 vs. 2019 LCOE: Utility-Scale PV}

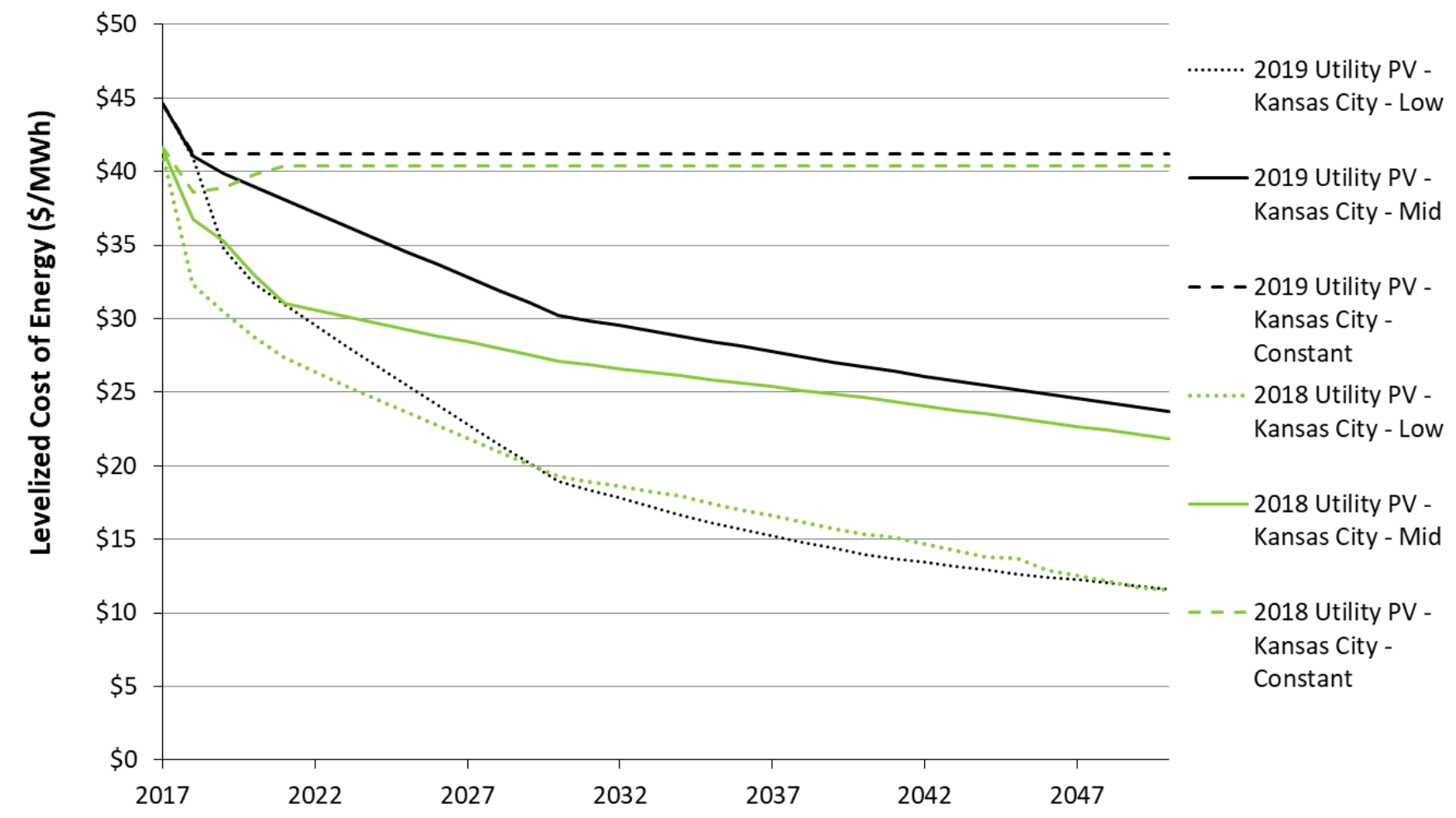

Utility PV ATB cost projections from 2019 (R\&D only) compared to 2018 (R\&D only)

Source: National Renewable Energy Laboratory Annual Technology Baseline (2019), http://atb.nrel.gov 


\section{Concentrating Solar Power}

- Technology Representation

- Molten salt power towers, with 10 hours of storage

- Three resource classes: Excellent (Daggett, California), Good (Phoenix, Arizona), and Fair (Abilene, Texas)

- Capacity factor excludes degradation, and ranges from $50 \%$ to $64 \%$.

- Projection Methods

- Literature survey: 13 projections from 7 institutions/sources

- Mid based on average of recent literature and NREL judgement of U.S. costs

- Low originates from the lowest CAPEX projections to 2025 and is extended to later years based on DOE research targets.

- Justification

- Power tower improvements arise from surface coatings that improve receiver efficiency and reduce O\&M costs, new salts allowing higher operating temperature and reduced TES cost, cost reductions throughout system due to increased temperature and efficiency, and heliostat cost reduction due to design and manufacturing improvements

- General improvements include supply chain efficiency and financing.

- New projections found from recent literature; projections, which are now separating power towers with molten salt, give strength to the technology representation and allow for comparison

- Older sources of information and projections removed (e.g., if a projection was based on older technology or the assumptions behind it were unclear)

- Notes

- $\quad$ Fair resource class changed from Las Vegas, Nevada, to Phoenix, Arizona. All resource classes have improved in the NSRDB. 


\section{8 vs. 2019 LCOE: Concentrating Solar Power}

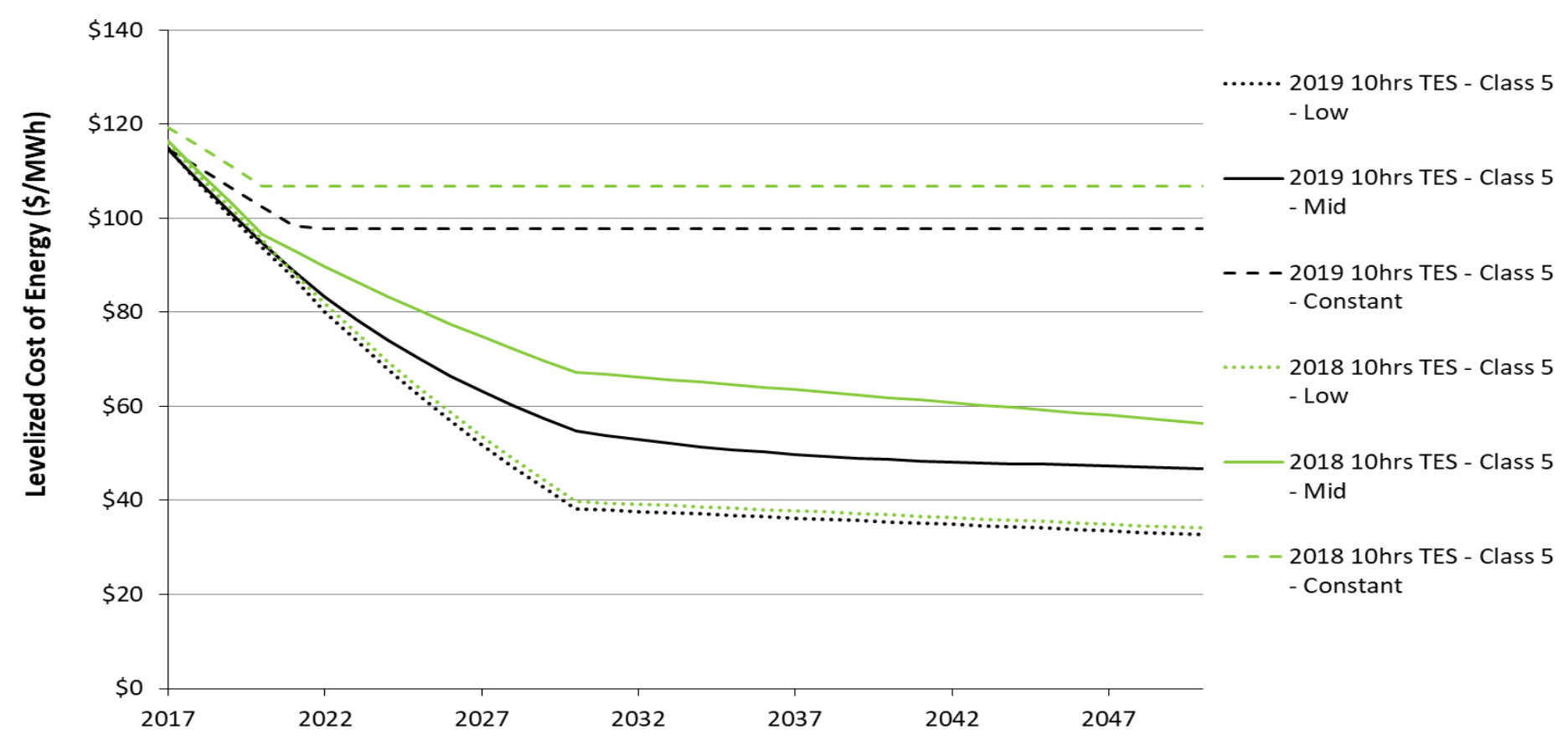

CSP ATB cost projections 2019 (R\&D only) compared to 2018 (R\&D only)

Source: National Renewable Energy Laboratory Annual Technology Baseline (2019), http://atb.nrel.gov 


\section{8 vs. 2019 CAPEX: Concentrating Solar Power}

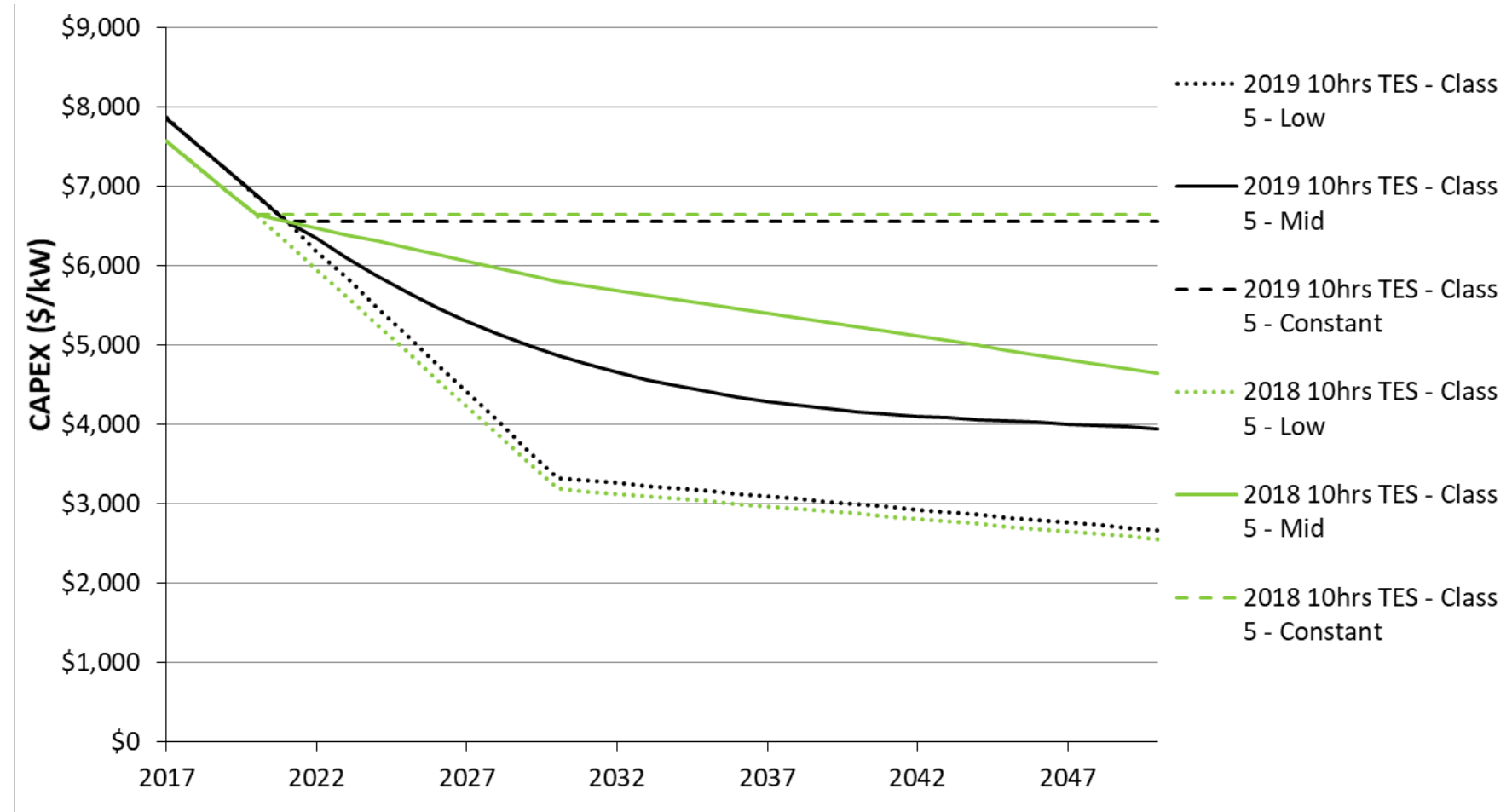

\section{CSP ATB cost projections 2019 (R\&D only) compared to 2018 (R\&D only)}

Source: National Renewable Energy Laboratory Annual Technology Baseline (2019), http://atb.nrel.gov 


\section{Geothermal}

- Technology Representation

- Represents flash and binary for hydrothermal and EGS

- Full site-specific resource data for current year

- Representative sites used for projections

- $\quad$ Projection Methods

- Incorporates GeoVision Study

- Justification

- Costs will be reduced through risk reduction in exploration and reservoir characterization, hightemperature tools and electronics for subsurface operations, development of reservoir engineering techniques and technologies that enable EGS, and advanced drilling

- Aligns with Geothermal Vision based on bottoms-up analysis with expert input. 


\section{8 vs. 2019 LCOE: Geothermal, Hydro/Flash}

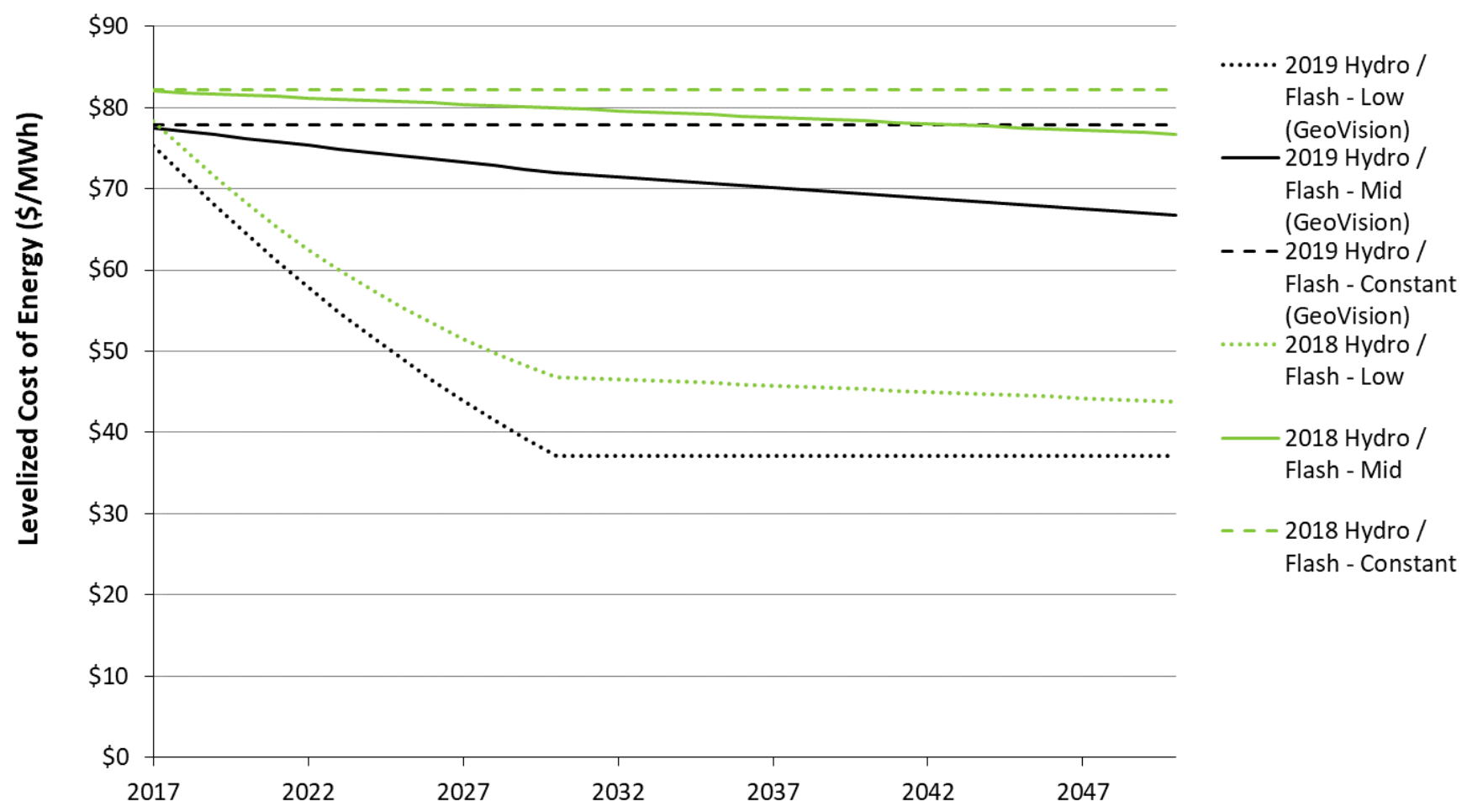

Geothermal ATB cost projections 2019 (R\&D only) compared to 2018 (R\&D only) 


\section{Hydropower}

- Technology Representation

- Four reference plants each for non-powered dams (NPD) and new stream development (NSD)

- Representative sites span dam size (3-30 ft or 30+ ft) and capacity (0.5-10 MW or 10+ MW)

- $\quad$ Projection Methods

- Uses scenarios developed for Hydropower Vision

- $\quad$ Low = Advanced Technology; Mid = Reference (NEMS exogenous cost reductions)

- Justification

- Cost reductions are based on implementation of engineering, design, and construction best practices, including "drop-in" systems; alternatives to steel; optimization using information systems; environmentally enhanced turbines; and improved permitting, licensing, and approval

- Aligns with Hydro Vision based on bottoms-up analysis with expert input

- $\quad$ Notes

- Updated for inflation and Hydropower Construction Index. 


\section{8 vs. 2019 LCOE: Hydropower, NSD 2}

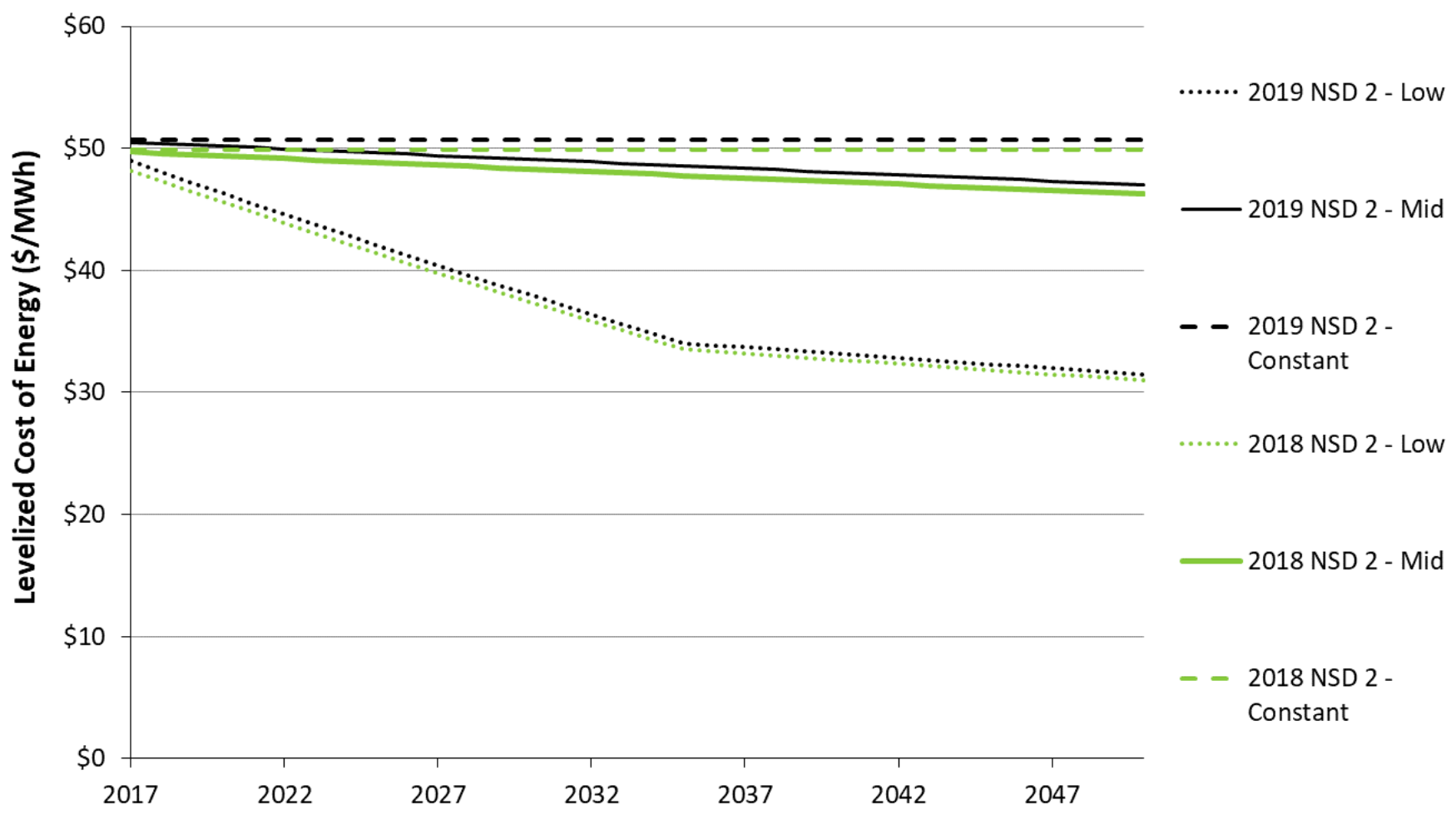

Hydropower ATB cost projections 2019 (R\&D only) compared to 2018 (R\&D only)

Source: National Renewable Energy Laboratory Annual Technology Baseline (2019), http://atb.nrel.gov 


\section{Battery Storage}

- Technology Representation

- Four-hour, utility-scale, 15-year, lithium-ion battery storage

- Projection Methods

- Uses scenarios developed from a new literature review

- Justification

- Ongoing battery development has reduced costs relative to previously-used literature survey

- Notes

- $\quad$ The ATB team has fielded comments about adding other types of storage. 


\section{8 vs. 2019 LCOE: Battery Storage CAPEX}

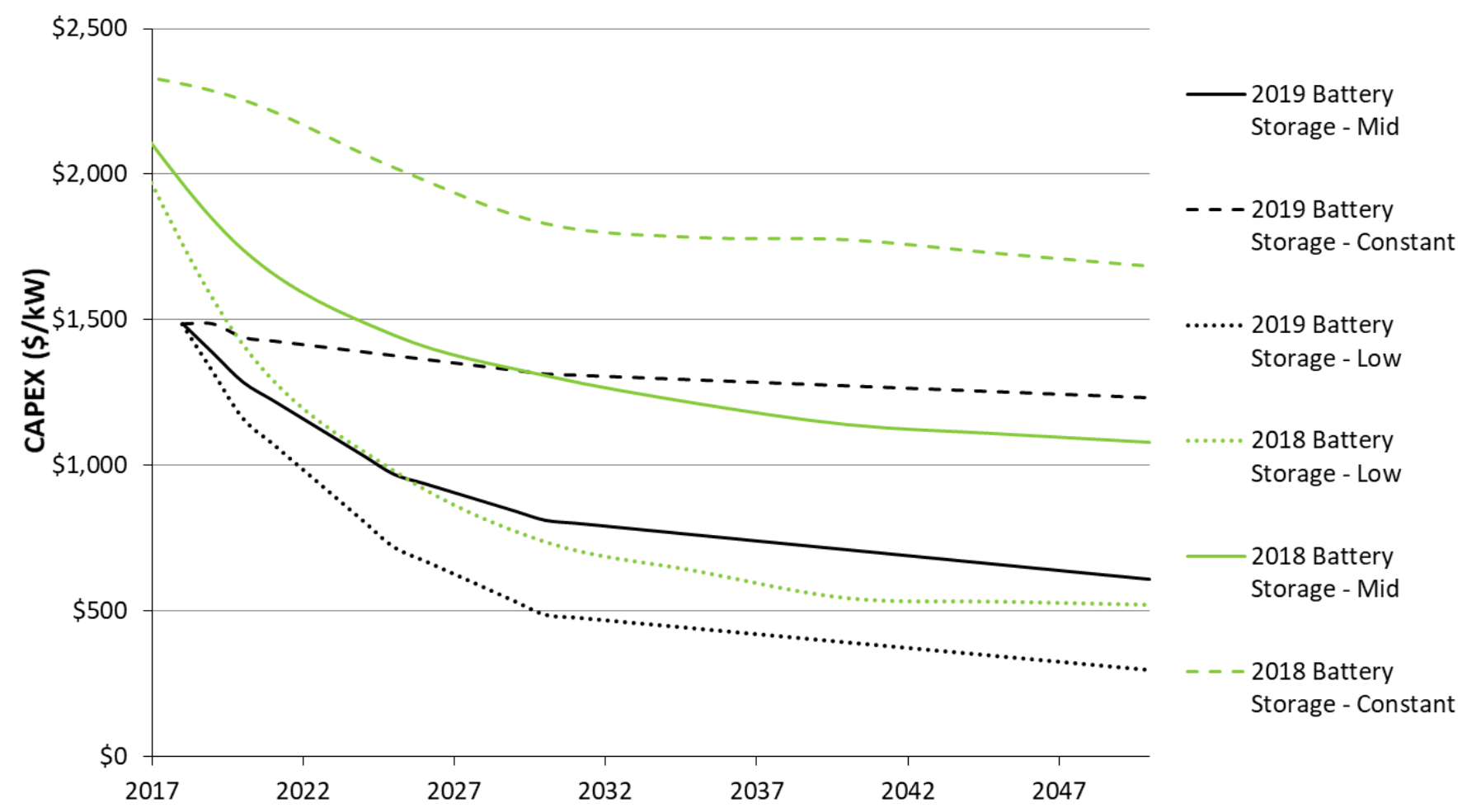

Battery Storage ATB cost projections 2019 compared to 2018 
Standard Scenarios

Preview 


\section{What are the Standard Scenarios?}

- Wide range of scenarios that examine the potential evolution of the power sector

- Consider both the cost and the value of the technologies when determining buildout

\section{The 2019 Standard Scenarios}

Mid-case
- Reference or Mid-level
Assumptions
Fuel Cost
- Low/High Oil and
Gas Resource

Demand
- Low/High Economic
Growth
- Vehicle Electrification

Technology Cost
- Low/High RE Cost
- Low/High Wind Cost
- Low/High PV Cost
- Low/High Geo Cost
- Low/High CSP Cost
- Low/High Hydro Cost
- Low/High Offshore
Wind Cost
- Low/High Battery Cost
- Nuclear Breakthrough

\section{Retirements}

- Accelerated Retirements

- Extended Lifetimes

- Endogenous Retirements

Policy
- National $80 \%$ RPS
by 2050
- $83 \% \mathrm{CO}_{2}$ Reduction
by 2050
- ITC \& PTC Extension
to 2030
- No State Policies

\section{Combinations}

- Low/High NG Price with Low/High RE Cost

- No State Policies + Low NG Price

- No State Policies + High RE Cost

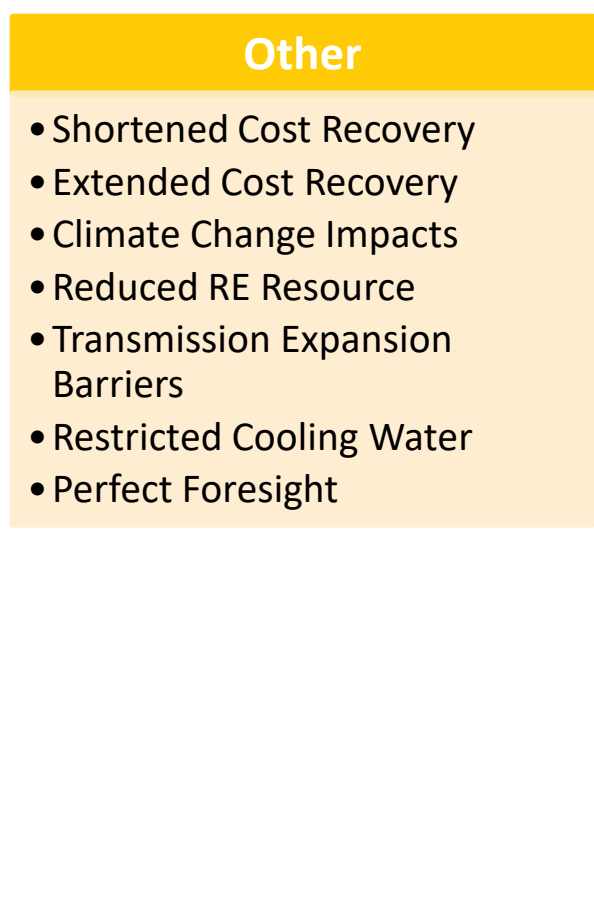




\section{Areas of Focus}

- The Standard Scenarios report highlights four areas of change from across the suite of scenarios:

- Interactions of cost and value of natural gas and renewable energy technologies

- Firm capacity in an evolving grid

- Impacts of increased renewable and clean energy mandates

- Regional generation mix trends.

- The report and scenarios are typically published in October each year. 
https://openei.org/apps/reeds

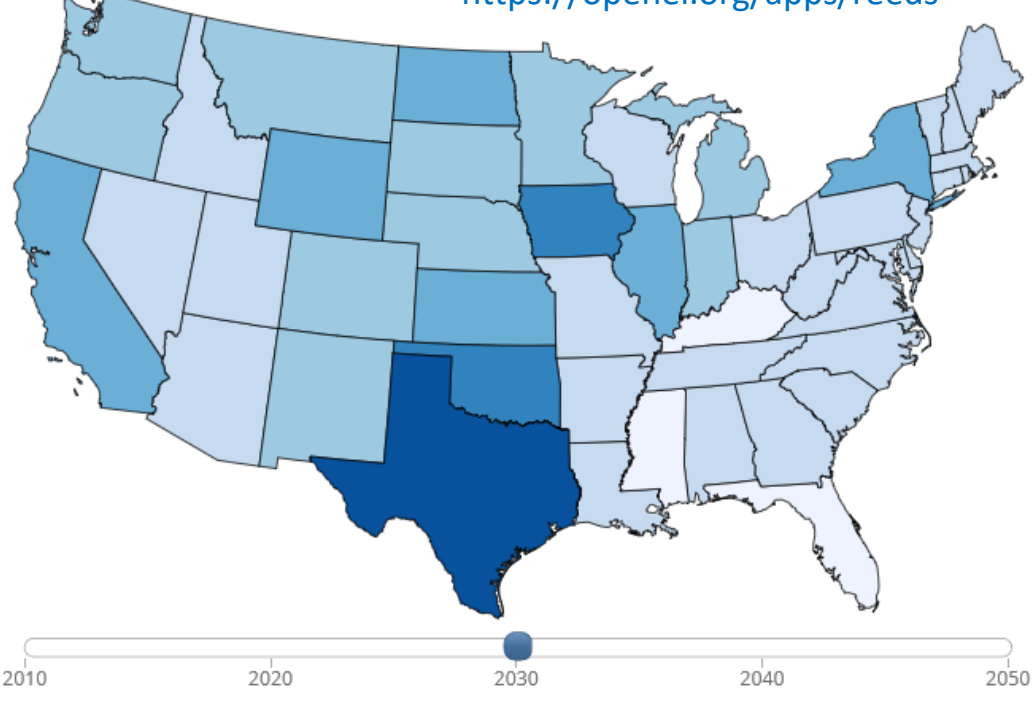

Publication Year

2018 .

Scenario 1:

Mid-Case Scenario -

Scenario 2:

None -

Select Display Region:

All (default) - Custom

Generation (2030):

Land-based Wind (TWh)

Generation -

Land-based Wind -

0

15.84-31.18

$31.18-85.74$

$6.19-15.84 \square 85.74-209.50$

Compare Technologies System Metrics

View and compare the contributions of each technology category to the total estimated generation or capacity.

Select All Clear All

Biopower
Coal
Geothermal
Imports
NG-CC
Nuclear
Oil-Gas-Steam
Storage
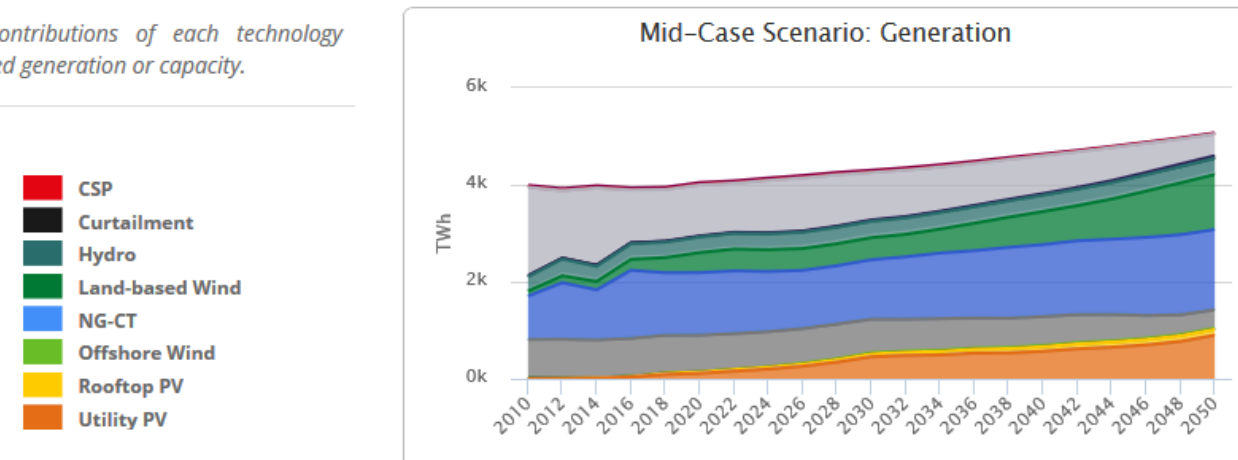


\section{Thank you.}

\section{www.nrel.gov}

NREL/PR-6A20-74273

The 2019 Annual Technology Baseline is available at atb.nrel.gov.

For full references, see https://atb.nrel.gov/electricity/2019/references.html.

This work was authored in part by the National Renewable Energy Laboratory, operated by Alliance for Sustainable Energy, LLC, for the U.S. Department of Energy (DOE) under Contract No. DE-AC36-08GO28308. Funding provided by U.S. Department of Energy Office of Energy Efficiency and Renewable Energy Strategic Priorities and Impacts Analysis and Office of Renewable Power. The views expressed in the article do not necessarily represent the views of the DOE or the U.S. Government. The U.S. Government retains and the publisher, by accepting the article for publication, acknowledges that the U.S. Government retains a nonexclusive, paid-up, irrevocable, worldwide license to publish or reproduce the published form of this work, or allow others to do so, for U.S. Government purposes.

\section{GNREL \\ Transforming ENERGY}

